\title{
Perinatal complications of children born after assisted reproduction treatments, is there a difference with those born by spontaneous pregnancy? results in 2 centers
}

\section{Summary}

Background: The assisted reproduction treatments (ART) have been increasing and it has been controversial if patients born after these have or not major adverse perinatal events and repercussions on their health.

Objective: To compare if there are more perinatal complications in a group of live births after ART in a private hospital against a group of spontaneous live births in a public institution.

Methodology: Observational, comparative, retrospective and cross-sectional study of patients from 2008 to 2018 at the Hospital Angeles, Mexico City (cases) and the Military Hospital of Specialties of Women from 2016 to 2017 (controls). In the case group, we included patients treated with ART, without age limit, either by their own embryos, donated embryos or by oocyte donation; we evaluated the presence or absence of obstetric complications (preeclampsia, gestational diabetes, threatened preterm delivery), and complications at birth (obstetric hemorrhage, early neonatal death, malformations).

In the control group, we evaluated the same factors. The statistical analysis was by descriptive statistics and by elaborating 2 X2 tables of contingency, to obtain odds ratios and relative risks.

Results: 124 cases, for the control group 290 patients. Regarding pregnancies in the case group, $62 \%$ were obtained with their own oocytes. The day of transfer with most pregnancies was day $3(47.5 \%)$. The average number of cycles to achieve pregnancy was 2.2 , the frequency of multiple pregnancies by ART was $23.4 \%$. When comparing groups, evaluating risks between them to present or not obstetric complications, we analyzed the most frequent ones; the group of cases was a factor that was associated with having no complications (OR 0.328 CI $0.188-.573$ ), but with a higher risk of preterm labor threat (OR 3.06 IC 1.725-5.456). Regarding other complications, no significant differences were found.

Conclusions: With the present study, we add evidence that there are no major obstetric and perinatal risks and complications after births of children conceived by ART.

Keywords: assisted reproduction treatments, spontaneous newborns, obstetric, perinatal, complications
Volume 5 Issue 4 - 2019

\author{
Héctor Salvador Godoy Morales,' Major \\ MD Germán Gabriel Palacios López, ${ }^{2}$ \\ Griselda Claribel Reyes Torres, ${ }^{3}$ Pablo Joaquin \\ Cervantes Mondragon, ${ }^{3}$ Daniel Vieyra Cortés, ${ }^{3}$ \\ Hilda Sanchez Hernández, ${ }^{3}$ Miguel Loyo Guiot ${ }^{3}$ \\ 'Director of ART Reproduction center, head of the Reproductive \\ Medicine Unit of the Hospital Angeles Pedregal, Mexico \\ ${ }^{2}$ Resident of the course of Reproductive Endocrinology and \\ Human Reproduction, Master of Health Sciences, attached to \\ the Military Hospital of Specialties of Women and Neonatology, \\ Mexico \\ ${ }^{3}$ Resident of the course of Reproductive Endocrinology and \\ Human Reproduction, Mexico
}

Correspondence: German Gabriel Palacios Lopez, Camino Sta. Teresa, I055-S, Heroes Padierna, Mexico City, 5549060765, Mexico, Email germanpalaciosl@hotmail.com

Received: July 12, 2019 | Published: August 14, 2019
Abbreviations: ART, assisted reproduction treatments; ICSI, intracytoplasmic sperm injection; IVF, in vitro fertilization; OR, odds ratio; $R R$, relative risk

\section{Introduction}

Since the first pregnancy obtained by Assisted Reproductive Treatments (ART) in 1978, these techniques have been increasing and they have also been converted to a controversial issue; the main goal has been to know whether patients born after the use of these techniques have major or no adverse perinatal events or repercussions on their health, both physical and psychological. ${ }^{1}$ In other words, the concerns about the welfare of children conceived with ART are as old as ART itself. The debate continues on whether the risks identified are attributable to the techniques of assisted reproduction or to the intrinsic characteristics of the parents that affect the quality and fertility of the gamete. ${ }^{2}$
Many authors have made research in this regard, as well as the risks of altering the normal development of gametes, embryos and the health of these children, ${ }^{3}$ there is a particular concern in the possibility of genomic imprinting disorders due to alterations in the establishment and maintenance of the imprint during gametogenesis, fertilization and embryological development. ${ }^{4}$ According to the hypothesis of the "evolutionary origins of adult disease", prenatal conditions can change the development and function of organs in developing organisms. The resulting physiological, metabolic and endocrine changes may be persistent and may predispose children to greater susceptibility to adverse obstetric events and in some cases, to disease in later life. It is still unknown, whether assisted reproduction procedures affect the epigenetic processes that occur during the critical points in early embryological development, and its short and long-term health consequences..$^{5-8}$

The use of these techniques has also been related to an increase in obstetric problems, especially those related to multiple pregnancies, 
low birth weight and other comorbidities of the mother that affect the neonate, ${ }^{9}$ which can result in birth defects and perinatal complications. ${ }^{10}$ There has been also a relationship with the treatment carried out, with the long-term effects on the cardiovascular system, metabolism, behavior, cognitive abilities and childhood cancers. ${ }^{11,12}$

In the present study, all the patients undergoing ART (private institution) were analyzed, included those whom it was possible to reach a live newborn, both by, own and donated gametes, either by In vitro Fertilization (IVF) or Intracytoplasmic Sperm Injection (ICSI); of which we followed up over time to assess if there were any complications during pregnancy and perinatal time, comparing it with a group of children conceived spontaneously (public institution). This information provides useful data since it is one of the few studies that has this information in our population.

\section{Material and methods}

Observational, comparative, cross-sectional and retrospective study, where we analyzed clinical records from patients with infertility diagnosis from 2008 to 2018 at the Angeles del Pedregal Hospital in Mexico city, using manual research of clinical records and from patients of the Military Hospital of specialties of Woman and Neonatology, from may 2016 to may 2017, from a data base that contained data recollected in an electronic system of patients that attended to the hospital by spontaneous pregnancies. In the case group, we included patients with confirmed diagnosis of pregnancy and live born, who had full clinical history and achieved it by ART, without age limit, treated with own embryos, donated embryos or by oocyte donation with partner or donated sperm, and that also all of these had complete clinical records that included hormonal concentration studies, quality of transferred embryo, day of transference, insemination technique and if there were obstetrical complications (preeclampsia, gestational diabetes, threat preterm delivery) and/or birth complications (obstetric hemorrhage, early neonatal death, malformations). In both groups, we excluded patients with diagnosis out of the established dates, incomplete clinical records and loss of pregnancy in the first 20 weeks of gestation by any cause.

The calculation of the sample size for the cases and controls study was performed using the prevalence of threat preterm delivery that is the most common obstetric event in patients with ART, ${ }^{13}$ being in ART $15 \%$ and $9.6 \%$ in spontaneous pregnancy according to data by the World Health Organization, we also used an $\alpha$ value of $0.5, \beta$ of 0.2 and $\mathrm{Z}$ of 1.96, after doing the calculations we got a sample size in the group control of minimum 286 patients. The sample of the cases group was conventional, and no probabilistic, it means that we included all patients that got pregnancy after ART in the study period; in the control group case, we used a database with 2,423 patients, and then made a random probabilistic sampling, using a web program that sort the cases, to select 290 patients. The used investigation method was the observation and data collection by a recollection data form, the source of information of the study was the clinical history taken from clinical records and a structured personal epidemiologic questionnaire designed ad hoc.

To perform the statistical analysis of results we analyzed them with data packages (Microsoft Excel $^{\circ}$ and IBM SPSS Statistics ${ }^{\odot}$ version 23) by descriptive statistic using measures of central tendency and dispersion for quantitative variables and proportions and frequency for qualitative variable. Crosstabs $2 \times 2$ (tables of contingency) were elaborated to compare the groups, obtaining Odds Ratios (OR), and Relative Risks (RR) to know if the conception way (spontaneous vs artificial) was associated with more perinatal adverse events, using the adjusted OR of Mantel-Haenszel to avoid confusing variables, with a confidence interval of $95 \%$ which symbolized that a $p$ value $<0.05$ was statistically significant. For qualitative variables, we used nonparametric tests (Mann-Whitney U) to compare differences.

This study was authorized by the investigation committee of Angeles del Pedregal Hospital and from the Military Hospital of Specialties of Woman and Neonatology and is strictly attached to the current guidelines by the general law of health in chapter I, Etic aspects in Human Body Article 17 (Mexican laws). Authors manifest no interest conflict.

\section{Results}

A total of 420 records of patients from the Reproductive Medicine Unit of the Angeles del Pedregal Hospital undergoing ART were analyzed. All of these patients were treated and attended by the author of this article; 296 were discarded because they didn't achieve pregnancy, leaving a final sample of 124 patients (group of cases) who achieved pregnancy and gave birth to a live newborn in that period of time; this represents a live newborn rate of $22.4 \%$. For the control group, a group of 290 patients was obtained after randomization of the database previously mentioned. The most frequent type of infertility of the patients treated in the Reproductive Medicine Unit was "Primary infertility" (60.5\%), followed by "Secondary infertility" (39.5\%). The reasons of consultation from the cases group are summarized in Table 1 , in which we can see that there is a high number of patients with age above 40 years, and that a high number of them has also a low ovarian reserve. The characteristics of the case group patients are summarized in Table 2, and finally their background is summarized in Table 3, in these tables we can see, that the majority of our patients have different comorbidities and most of them have been treated by Reproductive Surgery. Regarding, in the control group we only registered their age, which mean was 27.3 years (minimum of 15 years, maximum of 44 years).

Regarding the pregnancies in the case group, $62 \%$ were with their own oocytes, (the minimum age in this group was 25 years and the maximum age was 43 years) $19.4 \%$ by oocyte donation, and $18.6 \%$ by embryo donation (the pregnancy achieved at the oldest age was of 59 years old). The most frequent insemination technique was ICSI (40\%), followed by IVF (23.3\%), IVF and ICSI (15.3), and others $(21.4 \%)$ that included PICSI and IMSI. The transfer day on which the highest number of pregnancies were achieved were on day $3(47.5 \%)$, followed by day $5(31.5 \%)$, and day $2(21 \%)$, from which the quality " $8 \mathrm{C} 2+$ " (according to the Lucinda-Vick classification) got the highest number of pregnancies. The average number of attempts to achieve pregnancy was 2.2 cycles, with some patients getting pregnant in the first cycle, and others up to the ninth cycle (in the latter case the method was by embryo donation) Table 4 .

According to the type of transfer, the results in these patients were identical, $50 \%$ achieved pregnancy by fresh transfer, and the remaining $50 \%$ by devitrification. It is worth mentioning that $38 \%$ of pregnancies were achieved by gamete donation, therefore implying, it was due to devitrification. Following this train of thought, it could be said that the majority of pregnancies in patients with their own oocyte were achieved by fresh transfer. It is worth mention that the frequency of multiple pregnancies achieved by these techniques was $23.4 \%$, the rest were singleton pregnancies. Finally, in these ART cycles, the use of Endometrial Receptivity Assay (ERA biopsy) was necessary in only $7.5 \%$ of cases, and Preimplantation Genetic Diagnosis (PGS) in $6 \%$ of the cases (reasons are not specified because that isn't the main objective of the study). 
Table I Main reasons for consulting the reproductive medicine unit

\begin{tabular}{ll}
\hline Infertility factor & Frequency \\
\hline Age (> 40 years) & $32.20 \%$ \\
Uterine factor & $7.40 \%$ \\
Cervical factor & $1 \%$ \\
Tubal factor & $9.60 \%$ \\
Low reserve (<5 antral follicles) & $25.40 \%$ \\
Low responder (<3 oocytes captured in an IVF cycle prior to conventional doses in & $8.40 \%$ \\
patients without low responder characteristics) & $7.40 \%$ \\
Ovarian factor & $17 \%$ \\
Male factor & \\
\hline
\end{tabular}

Table 2 Main characteristics of the patients in the case group (excluding patients with pregnancies achieved by oocyte donation and embryo donation in the hormonal parameters)

\begin{tabular}{lllll}
\hline Characteristics of patients & Minimum level & Maximum level & Mean & SD \\
\hline Age & 24 & 58 & 37.23 & 5.73 \\
Basal AMH & 0.1 & 9.4 & 3.2 & 2.76 \\
Basal FSH & 1.7 & 16.1 & 6.87 & 19.2 \\
Infertility time (months) & 12 & 180 & 47.35 & 39.93 \\
Body mass index & 18 & 35 & 25.2 & 3.16 \\
\hline
\end{tabular}

Table 3 Main background of patients attended at the reproductive medicine unit

\begin{tabular}{|c|c|c|c|}
\hline Background of patients & Yes & No & $\begin{array}{l}\text { Non } \\
\text { specified }\end{array}$ \\
\hline $\begin{array}{l}\text { Previous low complex, assisted reproductive techniques (Scheduled Coitus or Intrauterine } \\
\text { Insemination) }\end{array}$ & $33.90 \%$ & $64.80 \%$ & $0.90 \%$ \\
\hline Previous pregnancy (newborn $33.5 \%$, abortion $59 \%$, ectopic pregnancy $7.5 \%$ ) & $39.50 \%$ & $60.50 \%$ & 0 \\
\hline $\begin{array}{l}\text { Previous surgery (myomectomy } 14.6 \% \text {, C-Section } 36 \% \text {, H-Scope I } 2 \% \text {, L-Scope } 32 \% \text {, Uterine } \\
\text { curettage } 5.4 \% \text { ) }\end{array}$ & $57 \%$ & $40 \%$ & $3 \%$ \\
\hline Inmunologic diseases & $2.40 \%$ & $92.70 \%$ & $4.90 \%$ \\
\hline $\begin{array}{l}\text { Uterine malformations (except endometrial polyps and fibromas, includes Mullerian } \\
\text { malformations) }\end{array}$ & $5 \%$ & $90.50 \%$ & $9 \%$ \\
\hline Ovarian Cyst & $11.20 \%$ & $83.80 \%$ & $5 \%$ \\
\hline Poliquistyc Ovarian Syndrome & $13 \%$ & $86.50 \%$ & $0.50 \%$ \\
\hline Uterine myomas & $26 \%$ & $70 \%$ & $4 \%$ \\
\hline Endometrial polyps & $11.50 \%$ & $84 \%$ & $4.50 \%$ \\
\hline Parents with multiple pregnancy & $14.50 \%$ & $80.50 \%$ & $5 \%$ \\
\hline Parents with infertility & $87 \%$ & $9 \%$ & $4 \%$ \\
\hline Hipotiroidism & $14.50 \%$ & $79.50 \%$ & $6 \%$ \\
\hline Ovarian Surgery & $7.20 \%$ & $87.40 \%$ & $5.40 \%$ \\
\hline Endometriosis & $27.40 \%$ & $70 \%$ & $2.60 \%$ \\
\hline
\end{tabular}

Citation: Godoy Morales H, Palacios Lopez G, Griselda Claribel RT, et al.. Perinatal complications of children born after assisted reproduction treatments, is there a difference with those born by spontaneous pregnancy? results in 2 centers. Int J Pregn \& Chi Birth. 20I 9;5(4): I53-I58. DOI: 10.15406/ipcb.2019.05.00167 
Table 4 Main obstetric characteristics by study group

\begin{tabular}{lll}
\hline Variable & Newborns after art & $\begin{array}{l}\text { Spontaneous } \\
\text { newborns }\end{array}$ \\
\hline $\begin{array}{l}\text { Way of birth } \\
\text { C-Section (90\%), } \\
\text { vaginal delivery (10\%) }\end{array}$ & $\begin{array}{l}\text { C-Section (10\%), } \\
\text { vaginal delivery (90\%) }\end{array}$ \\
$\begin{array}{l}\text { Average weight at } \\
\text { birth }\end{array}$ & Male & Male \\
$\begin{array}{l}\text { Average height at birth } \\
\begin{array}{l}\text { Average weeks of } \\
\text { gestation at birth }\end{array}\end{array}$ & $46.72 \mathrm{~cm} .7 \mathrm{~g}$ & $2938 \mathrm{~g}$ \\
$\begin{array}{l}\text { Average Apgar score } \\
\text { at } 5 \text { minutes after } \\
\text { birth }\end{array}$ & 36.1 weeks & $48.4 \mathrm{~cm}$. \\
\hline
\end{tabular}

When the pregnancies analysis of own oocytes vs donated ones was performed, the following information was found:

I. To achieve pregnancy by own oocytes, the average number of cycles was 1.98 .

II. To achieve it by oocyte-donation, the average of attempts was 2.2 cycles with a range of 1 to 6 attempts

III. For Embryo-donation the average was 2.1 cycles, with a range of 1 to 7 attempts.

When the comparison analysis between groups was performed, it was found that there were no statistically significant differences between achieving pregnancy by own oocytes against achieving it by donated ones (Mann-Whitney U 1435, p 0.1000). In the casecontrol analysis, the characteristics of the pregnancies are described in table 4 where we can note that the majority of births in the case group were by $\mathrm{C}$-section and the average weeks of gestation at birth fell in the range of premature birth. Regarding obstetric and perinatal complications, their main complications are described in Table 5, where the spontaneous newborns hadn't any complication in the $90 \%$ of cases, however, the majority of complications still, in both groups were very low. The risks calculation for obstetric complications development was analyzed, the most frequent ones were gathered and reported in Table 6.

The case group is considered being a factor associated with having no complications, and with a greater risk of preterm labor. There was no higher risk of preeclampsia, stillbirth or other complications leading to a C-section associated to birth rates after ART techniques. It is worth mentioning that when we performed the Student's t-test to compare the means of birth weight, there is a statistically significant difference between the weight obtained in newborns by ART against newborns by spontaneous births (Levene 0.496 , gl 352, p .000). When performing the analysis of the distribution for height at birth and weeks of gestation, since a normal distribution could not be obtained, we used the Mann-Whitney U test resulting in 2473 and 1895 respectively with $\mathrm{p} 0.006$ for the first case and p000 for the second case, which symbolizes there are statistically significant differences between the groups. Finally, to evaluate if there was a difference between APGAR at 5 minutes after birth, which correlates with a greater adaptation to extra uterine life and gives a prognostic value in neonatal reanimation, the Xi square test was performed, but we didn't found statistically significant when comparing both groups (p558).
Table 5 Obstetric complications by study group

\begin{tabular}{lll}
\hline Complications & Newborn after art & $\begin{array}{l}\text { Spontaneous } \\
\text { newborn }\end{array}$ \\
\hline None & $66 \%$ & $89.50 \%$ \\
$\begin{array}{l}\text { Preeclampsia } \\
\begin{array}{l}\text { Threat of premature } \\
\text { birth }\end{array}\end{array}$ & $22 \%$ & $0.30 \%$ \\
$\begin{array}{l}\text { Pulmonary } \\
\text { tromboembolism }\end{array}$ & $1 \%$ & $8 \%$ \\
$\begin{array}{l}\text { Fetal death } \\
\text { Gestational }\end{array}$ & 0 & 0 \\
$\begin{array}{l}\text { Diabetes } \\
\text { Malformations }\end{array}$ & $1 \%$ & $0.60 \%$ \\
$\begin{array}{l}\text { Premature rupture } \\
\text { of membranes }\end{array}$ & 0 & 0 \\
$\begin{array}{l}\text { Placental abruption } \\
\text { Placental acretism }\end{array}$ & 0 & 0 \\
$\begin{array}{l}\text { Obstetric } \\
\text { hemorrage }\end{array}$ & 0 & 0 \\
$\begin{array}{l}\text { Intrauterine Growth } \\
\text { Restriction }\end{array}$ & $1 \%$ & $0.60 \%$ \\
Oligohidramnios & $1 \%$ & $1 \%$ \\
\hline & & 0 \\
\hline
\end{tabular}

Table 6 Obstetric risks in the group born after ART vs spontaneous birth

\begin{tabular}{lllll}
\hline Complication & OR & RR & $\begin{array}{l}\text { Protective } \\
\text { factor }\end{array}$ & $\begin{array}{l}\text { Confidence } \\
\text { interval (95\%) }\end{array}$ \\
\hline None & 0.328 & 0.83 & 0.17 & $(.188-.573)$ \\
Preeclampsia & 0.94 & 0.05 & 0.95 & $(.898-.984)$ \\
Preterm birth & 3.067 & 2.55 & - & $(1.725-5.456)$ \\
Miscarriage & 1.007 & - & - & $(.997-1.016)$ \\
C-Section & 0.015 & 0.11 & 0.8 & $(.004-052)$ \\
\hline
\end{tabular}

*OR, odds ratio, $* \mathrm{RR}$; relative risk.

\section{Discussion}

Evaluating whether or not ART have repercussions on children's health has always been a controversial issue; despite its retrospective nature, the present study includes a good number of cases of ART cycles, with pregnancies achieved by own oocytes as well as donated oocytes and embryos, and it shows us the characteristics of the patients who were able to achieve pregnancy, as well as the comparison of perinatal complications with a group of newborns obtained spontaneously in a public institution.

There are several points to address when we study the characteristics of patients born by ART, such as age which is generally higher in patients seeking these treatments, as well as the number of comorbidities and hormonal alterations, which are the contributing factors to infertility, in this case we didn't do a deep analysis in these associations, but we made a complete descriptive record of the behavior of the population that was treated for infertility in our Reproductive Medicine Unit. In the analysis of differences, in that last topic, we mention that is important, but that we didn't evaluated it also, we just referred to whether there are differences between 
live newborns by cycles with fresh transfers versus frozen transfers. There are studies that comment that in frozen transfers live newborns, they have greater weight than those born by fresh transfers, ${ }^{14}$ in our study we compared the weight of both groups finding statistically significant differences in that children born by ART can have lower weight comparing to spontaneous births only, but not between fresh and frozen transfers, although, this could be influenced in turn, by the higher incidence of preterm delivery in the first group. We did not focus more on this variable, as the differences between weight and height did not cause additional complications.

The insemination techniques have been related to major birth defects and malformations, especially after ICSI, ${ }^{15}$ since the beginning of the millennium, although the concept has been modified over time and no studies have found more evidence that support it. ${ }^{16}$ In our study, for example, even though this was the most frequent insemination technique, we did not find any birth defects in the ART group either by own or donated oocytes and embryos. Despite the age of the patients, there was a patient with an embryo donation who achieved pregnancy between 58 and 59 years who had a newborn with no major malformations, neither in those with their own eggs over 40 years.

The risk of multiple pregnancy has been well established in ART cycles and there is evidence linking these techniques with the development of this type of pregnancy, specially related to the number of embryos transferred, preferring in some countries today the Single Embryo Transfer. ${ }^{17}$ In our study, the percentage was high: almost $25 \%$ had multiple pregnancy and in the same way this could have had an impact on the higher incidence, of preterm delivery in the group of ART-born, without directly affecting perinatal complications. It is interest that we cannot rule out that in some cases of singleton pregnancies, termination of pregnancy at lower gestational ages has not been influenced as much by medical concerns as those of the mother for avoiding complications, and the desire for birth in a "faster" manner. The relationship between preterm birth and having been conceived by ART techniques is clearly established. ${ }^{18}$

It is interesting that the incidence of NOT having complications according to the Odds Ratio is protective in the case of pregnancies due to IVF. This may be due to the number of cases or to the narrower prenatal control that is given to these products, compared to spontaneous patients who are more often born in public institutions and generally have poorer prenatal control, or are subjected to less screening tests, at least in our country. These conclusions are always going to be controversial because we will find data agains $\mathrm{t}^{19}$ or neutral. ${ }^{13}$

In the future, we would like to find out if there is an association between being born by ART, in terms of having infantile cerebral palsy, or alterations in cognitive development. The evidence suggests that there is no greater risk in the first group and that the intellectual development is multifactorial, even though in the children conceived by ART are more frequent to receive a greater education. For example, because the parents mostly have university studies and because they are sometimes considered as valuable products by their parents, due to the difficulty they went through to get them. ${ }^{20,21}$ It would also be interesting to carry out tests that evaluate the safety of these techniques. ${ }^{22}$

The initial idea to complete this study was to have a follow-up of at least 5 years to evaluate these patients and see their developments in different areas of life, but unfortunately, we did not succeed when we tried to contact their mothers, so we changed the approach and after that we draw interesting conclusions. Within the limitations of the study apart from its retrospective nature and low number of cases, we can mention that the criteria of management and the form of prenatal control can vary among the different centers, since one is private and the other public, which can for example be the reason that most of the case group children were born by $\mathrm{C}$-section compared to the control group that were born after spontaneous and vaginal birth. However, it is not above the value of the findings and it would be interesting to compare in the future control patients, attended in the private institution with the same doctor (which was the initial intention, but unfortunately, we only found 70 patients managed by spontaneous pregnancies, maybe because of the type of population that is attended in the unit of reproductive medicine that in its majority seeks attention by infertility).

\section{Conclusion}

The ART are safe, and haven't major perinatal complications. They are a good and safe option to the treatment of infertility even if they are not available as a benefit in some countries and in some of them are highly expensive and not considered in the insurance of public medical attention. They are an option for those couples which are looking for one of the biggest components of life cycle, which is reproduction, plus the right to leave offspring and raise a family. In some cases, some parents have been limited to look for this management apart from the economic issue (that we did not analyze in this study), because of the fear they have about complications related to the procedure.

With the present study, we have evidence that the use of ART in a private medicine center is safe in the majority of perinatal and obstetric complications, even when we compared the outcomes with a group of spontaneous newborns attended at a public hospital. These data adds evidence and supports other studies that have also found that in perinatal and obstetric issues there are low and limited complications.

\section{Acknowledgments}

We would like to acknowledge the facilites given by the Military Hospital of specialties of women by sharing their database and the support given in the present study.

\section{Conflicts of interest}

The authors of the present research manifest that there are no conflicts of interest.

\section{Funding details}

None.

\section{References}

1. Goldbeck L, Gagsteiger F, Mindermann I, et al. Cognitive development of singletons conceived by intracytoplasmic sperm injection or in Vitro fertilization at age 5 and 10 years. J Pediatr Psychol. 2009;34(7):774781.

2. Owen CM, Segars Jr JH. Imprinting disorders and assisted reproductive technology. Semin Reprod Med. 2009;27(5):417-428.

3. Hanevik H, Hessens D, Sunde A, et al. Can IVF influence human evolution? Hum Reprod. 2016;31(7):1397-1402. 
4. Amor DJ, Halliday J. A review of known imprinting syndromes and their association with assisted reproduction technologies. Hum Reprod. 2008;23(12):2826-2834.

5. Fauser B, Devroey P, Diedrich K, et al. Health outcomes of children born after IVF/ICSI: a review of current expert opinion and literature. Reproductive BioMed Online. 2014;28(2):162-182.

6. Bonduelle M, Van Assche E, Joris H, et al. Prenatal testing in ICSI pregnancies: incidence of chromosomal anomalies in 1586 karyotypes and relation to sperm parameters. Human Reprod. 2002;17(10):2600 2614.

7. Chantot Bastaraud S, Ravel C, Siffroi JP. Underlying karyotype abnormalities in IVF/ICSI patients. Reprod Biomed Online. 2008;16(4):514-522.

8. Georgiou I, Syrrou M, Pardalidis N, et al. Genetic and epigenetic risks of intracytoplasmic sperm injection method. Asian Jour of Androl. 2006;8(6):643-673.

9. Engin T, Yagmur H, Seyhan A, et al. Short and long term outcomes of children conceived with assisted reproductive technology. Eur J Obstet Gynecol Reprod Biol. 2016;207:129-136.

10. Declercq E, Luke B, Belanoff C, et al. Perinatal outcomes associated with assisted reproductive technology: the Massachusetts Outcomes Study of Assisted Reproductive Technologies (MOSART). Fertil Steril. 2015;103(4):888-895.

11. Wagenaar K, Van Weissenbruch MM, V Leeuwen FE, et al. Selfreported behavioral and socioemotional functioning of 11- to 18-yearold adolescents conceived by in vitro fertilization. Fertil Steril. 2011;95(2):611-616

12. Abdel Mannan O, Sutcliffe A. I was born following ART: how will I get on at school? Semin Fetal Neonatal Med. 2014;19(4):245-249.
13. Perinatal risks associated with assisted reproductive technology. Committee Opinion No. 671. ACOG Obstet Gynecol. 2016;128:61-68.

14. Spikjers S, Willem J, Schats R, et al. Fresh and Frozen-Thawed Embryo Transfer Compared to Natural Conception: Differences in Perinatal Outcome? Gynecol Obstet Invest. 2017;82(6):538-546.

15. Hansen M, Kurinczuk J, Bower C, et al. The risk of major birth defects after intracytoplasmic sperm injection and in vitro fertilization. $N$ Engl J Med. 2002;346(10):725-730.

16. Hindryckx A, Peeraer K, Debrock S, et al. Has the Prevalence of Congenital Abnormalities after Intracytoplasmic Sperm Injection Increased? The Leuven Data 1994-2000 and a Review of the Literature. Gynecol Obstet Invest. 2010;70(1):11-22.

17. Henningsen A, Gissler M, Skjaerven R, et al. Trends in perinatal health after assisted reproduction: a Nordic study from the CoNARTaS group. Human Reprod. 2015;30(3):710-716.

18. Ortiz M, Acevedo B. Assisted reproductive techniques and child health Rev Ped de Aten Prim. 2010;12(48):651-671.

19. Pandey S, Shetty A, Hamilton M, et al. Obstetric and perinatal outcomes in singleton pregnancies resulting from IVF/ICSI: a systematic review and meta-analysis. Hum Reprod Update. 2012;18(5):485-503.

20. Porta Ribera, Tremols V, CMunar Mut, et al. Monitoring neurodevelopment in children born as a result of using assisted reproduction techniques. Rev Neurol. 2009;49(9):463-466.

21. Leena R, Tiitinen A, Lindblom J, et al. Mental health and developmental outcomes for children born after ART: a comparative prospective study on child gender and treatment type. Hum Reprod. 2016;31(1):100-107.

22. Brison D, Roberts S, Kimber SJ. How should we assess the safety of IVF technologies? Reprod BioMed Online. 2013;27(6):710-721. 